\title{
Consideraciones sobre el amor romántico en el cine extranjero
}

\author{
Considerations on Romantic Love in Foreign Films \\ Andrea V. Hernández-Ruiz ${ }^{a}$ y Claudia Sandoval-Zamorano ${ }^{b}$
}

\begin{abstract}
:
This essay aims to explain how foreign films influence the perpetuation of romantic love in the Mexican context. The history and characteristics of this concept are briefly addressed, in addition to the normative thoughts associated with gender roles, leading to a reflection on what love means in reality, apart from the big screen, as well as the importance of the raise of awareness about the myths surrounding romantic love and the cultural and social consequences of these myths.
\end{abstract}

Keywords:

Foreign films, romantic love, stereotypes, myths

Resumen:

El objetivo de este ensayo es explicar cómo influyen las producciones cinematográficas extranjeras en la perpetuación de un constructo como el amor romántico en México. Se aborda brevemente la historia y características atribuidas a dicho concepto además de los pensamientos normativos asociados a los roles de género, llevando a la reflexión acerca de lo que lo que significa el amor en la realidad fuera de la gran pantalla, así como la importancia de hacer consciencia sobre los mitos existentes alrededor del amor romántico y las consecuencias sociales a nivel cultural que generan dichos mitos.

\section{Palabras Clave:}

Cine extranjero, amor romántico, estereotipos, mitos

\section{Introducción}

"Ama el cine, ama el cielo, las mariposas y las malditas flores, ama a [...] pero ama algo" ${ }^{[1]}$.

Las razones por las que la raza humana, hombres y mujeres han enfocado gran parte de su historia a tratar de entender el amor a través de obras filosóficas, literarias, escénicas, musicales, plásticas, fotográficas, etc., pueden parecer misteriosas. Esta tarea, ha significado a lo largo del tiempo para artistas, poetas y románticos en su estudio. Para comenzar el siguiente artículo debe mencionarse que existen distintos tipos de amor, e incluso estilos de amar. En esta ocasión se hará un análisis sobre el constructo de amor romántico, que ha tenido gran importancia al momento de moldear las relaciones interpersonales y establecer parámetros en actividades cotidianas como la bú squeda de parejas.

El amor romántico ha sido un tema de interés en distintos campos de estudio desde hace varios siglos. El concepto del amor ha transcurrido y evolucionado desde una civilización a otra, por ejemplo, en la Grecia Antigua se realizaban obras literarias y teatrales que giraban en torno a este tema, como lo son los mitos de "Ulises y Penélope", "Andrómeda y Perseo", "Apolo y Dafne”, etc. De la misma forma, en la Roma Antigua se encuentran obras como "los jóvenes", "las jóvenes", entre otras, destacando que el famoso día de San Valentín o "día de los enamorados" tiene sus orígenes en la ahora Italia.

En Era Anglosajona aparecen ejemplares literarios, pero es hasta la Edad Media que el concepto de amor romántico comienza a tomar forma; como el amor cortés, que estaba fuertemente asociado a los

\footnotetext{
a Autor de Correspondencia, Universidad Autónoma del Estado de Hidalgo, Instituto de Ciencias de la Salud, https://orcid.org/0000-00028933-5434, Email: avanessahruiz@ gmail.com

b Universidad Autónoma del Estado de Hidalgo, Instituto de Ciencias de la Salud, https://orcid.org/0000-0001-8689-0064, Email: claudiasan91@ hotmail.com
} 
caballeros. En el periodo Tudor, influenciado por la culturainglesa, se manifestó en formas como con sonetos y poemas, entre sus autores principales destacó William Shakespeare, con su obra "Romeo y Julieta" que se repite constantemente en las producciones de nuestra época y que tiene a bien ser la obra que mejor representa el concepto de amor romántico. En la Era Victoriana el amor comenzaba a asociarse con el de matrimonio, mientras que en las épocas anteriores se entendía el casarse como formar parte de un contrato social que debía ser beneficioso económicamente, la Era Victoriana sienta las bases del matrimonio por amor, en donde quien se casa lo hace sin buscar ben eficios sociales o monetarios. Esta idea es la de mayor reproducción y prevalencia en occidente ${ }^{[2]}$.

Este paso del tiempo ha permitido moldear la representación del amor y han logrado colocarlo como casi inalcanzable. Una de las formas más efectivas para la popularización del amor romántico y que ha contribuido a su relativa estabilidad a pesar del cambio generacional son los medios de comunicación o mass media, nombrados así por su alcance masivo, entre los que se encuentran la radio, la prensa y el cine. Estas formas de comunicación han tenido mayor alcance en la actualidad gracias a los avances tecnológicos y el uso popular del internet. Los medios de comunicación masiva sirven a la propagación de ideas y a la reproducción de las normas culturales, es decir, se convierten en transmisores de lo socialmente aceptable, estas normativas no excluyen al amor, y mucho menos al amor romántico.

En México, por ejemplo, la idea de "conocer a la media naranja" ha ganado popularidad y hay personas que afirman que no han llegado a encontrar con su otra mitad. En este sentido, es importante conocerel concepto de amor romántico, los mitos que lo rodean como el final feliz y su contraste con otros tipos de amor. En el cine extranjero, sobretodo en el hollywoodense, encontramos un constante refuerzo a las creencias en torno al amor romántico y que, como consecuencia de su popularidad, se reproducen también en el contexto mexicano. De la misma forma, se encuentran los estereotipos de género reproducidos en las producciones cinematográficas, así como los modelos a seguir, constructos utópicos posibles solo en pantalla grande. Así como todas aquellas guías de comportamiento que son un fenómeno sociocultural que merece el interés de la reflexión y una mirada a las consecuencias que todos estos eventos provocan en la sociedad mexicana.

\section{Desarrollo}

\section{Acerca del amor}

De acuerdo a Sangrador [3], el amor es un objeto de estudio complejo que si se le separa de los estudios realizados desde perspectivas biológicas, psicofisiológicas, sociológicas y filosóficas no abarca en su totalidad sus características, por lo que deja elementos excluyentes, es decir, que no debería estudiarse únicamente desde el método científico e incluso pone en duda esta posibilidad. En una ponencia del mismo año, Bachoir $^{[4]}$ asegura que es un término de difícil conceptualización, "es muchas cosas" menciona, incluso expone la idea de que con cualquier definición meticulosamente medida y cuantificada se corre el riesgo de no abarcar el concepto puro, por lo tanto, el amor es un constructo complejo de difícil abstracción. Sin embargo, se necesita de alguna definición para poder aludir a todas sus diferentes expresiones en el mundo socio-cultural.

Diversos autores y autoras mencionan el concepto del amor a través de su producción (académica, filosófica, artística, etc.) y tienen un carácter instrumental ya que fungen como ejemplo y modelo representativo del comportamiento social, añadiendo símbolos, pautas y significados al ideal del amor, sobre todo del amor romántico ${ }^{[5]}$. Alan Badiou ${ }^{[6]}$ menciona que el amor es un pilar central de las personas, ya que implica procesos y estados subjetivos importantes, que en su concepción va en contra del individualismo en el que se dirige la sociedad actual. En este sentido, el amor podría entenderse como una guía de comportamiento presente en las relaciones y procesos interpersonales en la que se percibe claramente cuando alguien es amado o no, por ejemplo; cuando se es un niño se tiene la idea del amor fraternal, que al poseerlo y ser infantes trae consigo diversidad de cualidades y expectativas positivas a futuro; pero cuando no se tiene, las expectativas cambian y generalmente son orientadas al lado opuesto. Esto quiere decir que las conductas de una persona pueden determinarse por la ausencia de experiencias amorosas y de cuidado.

Por otro lado, José de la Serna en su libro titulado "De amor y otras muertes horribles", incluye un poema que lleva como título "ahora, amor, amor". En el poema, el autor asegura que el amor debe ir más allá de las acciones positivas y valoradas culturalmente, implicando mayores actos de valentía, dejando de lado modelos y estereotipos, implica que es necesaria la sensación de sentirlo hasta "debajo de la piel" un sentimiento que no puede entenderse de forma cuantitativa o científica. Lo que presenta una dicotomía difícil de entender, por un lado, un sentimiento 
incomprensible y, por otro, tan fácilmente entendido y reproducido por los medios masivos. Es cierto que es un sentimiento complejo, sin embargo, es una necesidad básica: el sentirnos amados ${ }^{[1]}$.

\section{Medios de transmisión en masa: el cine}

Existe gran diversidad de medios de transmisión de la información entre los que se encuentran los productos audiovisuales de ficción, populares en el cine. Es importante detenerse a pensar en que estos medios reproducen una idea del amor romántico como protagónico, es decir, como la única forma de ejercer y vivir el amor en pareja. Mediante diferentes filmes, se reproducen las pautas de comportamiento a seguir en dicho proceso, encasillando los roles asignados a las mujeres y hombres, que frecuentemente están asociados a moldes de la masculinidad hegemónica y la feminidad normativa que generalmente son comprendidos como conceptos dominantes ${ }^{[7]}$.

En México la industria del cine ha crecido alrededor de un $8.4 \%$ en los últimos 10 años, no por ello significa que industrias del cine mexicano como Cinemex y Cinepolis promueven cine nacional, prueba de ello son las carteleras, a pesar de que existen festivales y promociones que intentan popularizar el cine mexicano, este se encuentra con que sus bajos presupuestos les impiden explorar y experimentar con los géneros cinematográficos, limitándose a producir una y otra vez las comedias románticas que se estrenan con alarmante frecuencia ${ }^{[8]}$.

Zaldivar $^{[9]}$ menciona la importancia de generar conciencia acerca del cine extranjero y los barajes culturales que promueve, incluso se hizo una comparación en el año 2002 acerca de la cinematografía norteamericana en México, de la cual el $73.5 \%$ fue americana, y el $5.88 \%$ fue cine nacional, no es de sorprenderse ya que la comunidad mexicana tiene la tendencia a consumirmercancía de otros países, dejando de lado lo producido en el propio país. El cine asiático también tiene un territorio cubierto en México, además de otros medios de difusión con los que cuenta esta cultura y como uno de sus fuertes, son los comics, con presencia en la nación desde la década de $1980^{[10]}$. Tal es el caso que incluso en Japón, la idea que representa a la pareja tradicional es de dos personas heterosexuales, siendo común la menor aceptación a parejas con otras preferencias, las mujeres se perciben como recatadas y poco extrovertidas, mientras que los hombres expresan seguridad ante ellas, dejando los sentimientos como algo más personal que difícilmente muestran [11].

Para hacer referencia a estas mismas comedias románticas, basta mirar películas como "500 días con ella”, estrenada en 2009 y producida por el estudio Fox, que narra la historia de cómo un chico se conoce con una chica y se enamora de ella a primera vista, pasan diversos sucesos que hacen que estos dos personajes se empiecen a conocer. Tom, el protagonista, le da sentido a su vida, haciendo como si el amor en pareja atrajera la felicidad y el éxito. A lo largo de la relación Tom hace todo lo posible por estar bien con Summer (su coprotagonista) y traspasar la aparente barrera emocional que ella implanta durante la película, y recuerda a las frases estereotipadas de "el amor todo lo puede", "el amor puede cambiar a una persona", y "si se está enamorado de alguien y es amor 'verdadero', este es reciproco".

Eventualmente, Summer deja a Tom, y le dice lo prefiere como amigo, cabe mencionar que Summer parece no tener responsabilidad afectiva sobre las emociones de Tom, cabe señalar que la película está narrada desde su punto de vista. Al separarse, se reproduce la idea de que él comienza a ser infeliz y de nuevo nada le da sentido a su vida "el sentido de vida te lo da otra persona, tu media naranja". Lo despiden, no sonríe, consume bebidas alcohólicas y pierde toda conducta de autocuidado, recluyéndose en su casa. Después de algún tiempo, encuentra nuevamente a Summer, y ella tiene un anillo de bodas, que al parecer le dio otra persona, lo que da a entenderque ahora Summer logro 'conocer el verdadero amor' y por ello decidió casarse, reforzando la idea de que el amor romántico termina en compromiso".

La película logra de alguna manera que Tom (el hombre) sea victimizado y Summer (la mujer) sea la mala de la historia, lo que no deja ver la realidad de la situación, que ella fue sincera al decirle que no podían seguir como pareja, pero que podían ser amigos. En otras palabras, la tarea es cambiar el mensaje y normalizar el hecho de que una persona, ya sea hombre o mujer, puede y tiene el derecho a cambiar de opinión con respecto a sus vínculos sexoafectivos y no tiene que ser acusada o victimizada por ello.

Este tipo de enseñanzas se proyectan cientos de veces a través de la pantalla grande, se ha hecho durante décadas. Otra película americana que retrata muy bien este modelo a seguires "Posdata: Te amo", la historia gira en torno a dos personas que se conocieron y tuvieron su final feliz que los lleva al matrimonio. Sin embargo, a través de la película, se reproduce la idea del amor eterno, ya que el varón protagonista muere a causa de una enfermedad crónica, pero este se las ingenia para que aún después de su muerte ella lo recordara durante un año entero, hasta ayudarla a superarlo.

Otro ejemplo puede encontrarse en la película "Tu nombre" o mejor conocida como "Your name", promueve ideas como la del destino entre dos personas, así como que la fortaleza del amor vencerá incluso con el tiempo, es decir, frente a cualquier adversidad y así como 
las producciones antes mencionadas, se encuentran más filmes del cine extranjero. Cabe decir que las guías de conducta de cómo suceden las relaciones amorosas o el amor romántico, se expresan en guiones de películas como productos finales, es decir, la culminación deber ser el "felices por siempre". Sin embargo, no se deben dejar de lado las conductas delimitadas de cada personaje dentro de lo femenino y masculino, dicho de otra forma, las pautas de comportamiento de los hombres y las mujeres que forman el conjunto de subjetividades que dan forma a la concepción del amor romántico, que se visualiza como una meta y tiene poco lugar a la crítica.

Bandura, a través de su teoría del aprendizaje social o aprendizaje vicario, dice que se aprende por medio de la observación a través de modelos de conducta ${ }^{[12]}$. Esta teoría asegura que se es más susceptible a imitar al modelo que más se parece al "mí mismo" físicamente, así se logra unimismar las características propias de uno con dicho modelo. Esto sucede mediante identificación del sexo, es decir un hombre suele identificarse más rápidamente con un modelo masculino; siempre y cuando dicho hombre se reconozca como hombre, como resultado final las conductas son apropiadas por el individuo y esto sucede de igual manera con las mujeres.

Por lo tanto, la identificación y la apropiación de las características de los modelos con los cuales una persona se identifica son los que van a reproducir y trasmitir el sujeto en el mundo social, permitiendo así que en la población se sigan con estos estereotipos acerca del amor, como los ya mencionados. Resulta claro que el ideal del amor romántico que se reproduce a través del cine es; sucede a primera vista, debe de ser reciproco, puede cambiar a las personas, el amor atrae la felicidad, es símbolo de éxito, el amor todo lo puede, debe terminar en compromiso, el amor va más allá de la muerte y otras adversidades, las personas involucradas en el lio amoroso están destinadas a estar juntas, solo por mencionar algunas.

\section{El aprendizaje cultural actual}

La población en general ha aprendido a vivir dentro de las normativas de la cultura, los sistemas políticos y económicos al que pertenece el país, sin embargo, pueden resultar limitantes y dañinos para la persona inmersa en dicho sistema, ya que no permiten al sujeto vivir en esencia de su ser sino vivir para el sistema. "No hay tiempo para el amor" tiene que ponerse en duda en el sistema capitalista, donde las aspiraciones en algún punto del tiempo dejaron de ser trabajar para vivir, para convertirse en vivir para trabajar.

Esto explicaría porque en la sociedad actual la vida es mayormente sedentaria y ya no hay tiempo para uno mismo, ni para aquellos que pertenecen a nuestro círculo cercano, haciendo que sea más sencillo y cómodo vivir el amor a través de una pantalla y de los mass media, que más que vivir será ver (como espectadores) el amor en grandes escenarios, permitiendo experimentar sensaciones en su mayoría agradables en un desarrollo de 120 minutos que hace creer que la información de los sucesos que ocurren las historias en el cine, suceden en la vida real, y es justo la cuestión, la falta de crítica a los modelos hegemónicos y el atrevimiento de la población a reinventar las formas del amor ${ }^{[13]}$.

El amor romántico es un concepto que se basa en sentimientos y emociones que se añoran y se persiguen. Existe una tendencia ciega en el modo de alcanzarlo, y es por ello que existen tantas guías de cómo debe de ser el amor romántico, cómo debe de actuar cada hombre y cada mujer en sus relaciones interpersonales para conseguir enamorarse, creando relatos fantasiosos, entendidos desde un principio como verídicos. Para entender porque las masas son tan susceptibles a esta información, es importante considerar que la información presentada en el cine, de una u otra forma no engloba todas las situaciones reales de lo que es o puede ser el amor romántico o lo que genera en la vivencia real en sí, que dicha información deba ser considerada un mito ya que no hay forma de asegurar su totalidad.

El desarrollo de los mitos es una necesidad básica del ser humano, innata a sus cogniciones, lo que los hace la piedra angular de creaciones históricas y psicológicas, promoviendo patrones y datos que permiten decodificare interpretar el mundo incluyendo caracteres externos e internos ${ }^{[14]}$. Entre sus funciones está el explicar fenómenos incomprensibles, dando cierta calma a la psique y, como es evidente a lo largo de este ensayo, el amor no escapa de estos mitos.

Dicho mito se regula y se reproduce mediante una misma idea, ya sea en el cine, el teatro, la literatura, en la radio o en los propios relatos, son dos personas que deben estar unidas y pese a cualquier adversidad (antigua como dragones, o moderna como trabajos separados o una amiga entrometida) deben reencontrarse para poder alcanzar la felicidad y la plenitud, por lo tanto, es fundamental reconocer que existen ideas patriarcales atravesadas regulando los constructos de los roles femenino y masculino, es decir, el varón como el fuerte, valiente, caballeroso, el personaje protagónico activo, y la mujer como sensible, la espera, tolerante, cuidadora, pasiva y esperando ser salvada (por él). Estas guías también son visibles en las producciones por Disney como en "La bella y la bestia", "La bella durmiente", "Rapunzel", "Blancanieves y los siete enanos", "Cenicienta", "La sirenita" y otras más ${ }^{[15]}$. A su vez es importante interrogarse acerca del papel del 
príncipe azul y la princesa que son personajes que promueven la división de los roles sexuales, lo que lleva a cuestionarse que tanto de lo que se produce en estas películas: el amor y sus parámetros.

Uno de estos parámetros que cabe mencionar brevemente, es la concepción de la monogamia, que tiene una estrecha relación con la idea del amor romántico. Para diversos investigadores, no es una verdad incuestionable que los humanos estén hechos para la monogamia, incluso se permiten dudar del cómo a través de la evolución con la teoría de Darwin y observando mediante investigaciones científicas y rigurosas a los Chimpancés y Bonobos, parientes cercanos en el desarrollo de la raza humana, se demuestra de que no son monógamos, incluso se desarrolla la idea de que si los animales tienen sexo o copulan para sobrevivir y perpetuar la especie por medio de la reproducción, cómo es posible que la raza humana instintivamente no busque lo mismo. Se sabe también de las diferencias biológicas de los humanos con los monos y las demás especies ${ }^{[16]}$. Las relaciones humanas varían dependiendo de los contextos en los que estén inmersas las personas y existen incontables formas, pueden ser abiertas, de unión libre, parejas múltiples, poliamor, swingers, intercambio de parejas, etc. Debe pensarse que la monogamia no es una obligación, sino un acuerdo que viene con muchos otros dentro de una pareja, si se quiere tener una pareja monógama, es importante que se ponga sobre la mesa el cuidado y el respeto a través del diálogo ${ }^{[3]}$, ejercicios que pueden resultar hasta abu rridos para el amor romántico, ya que nadie hace una película sobre cómo se puso de acuerdo con su pareja para tener una relación exclusiva y todo fue muy bien.

\section{Conclusión}

La forma incuestionable de amor romántico que prevalece gracias a los recursos del sistema, como los medios masivos de comunicación, entre ellos el cine extranjero, que es el de mayor consumo en la población mexicana, convierten la forma de amar en una normativa [17]. Asimismo todo aquél que no respeta lo normativo es suprimido en una gran diversidad de formas, no permitiendo a quienes estén sujetos a esta conceptualización del amor, el ser libres, incluso no darse cuenta de sus formas de expresión patriarcales, sexistas y violentas, formando parte de sus creencias más arraigadas y normalizando cualquier acto agresivo o violento hacia los elementos del proceso del amor romántico, fortaleciendo la desigualdad de género por medio de hostilidades escritas, de lenguaje y actuadas, haciendo común el ciclo de violencia emocional y físico aprendido, propagando ideas misóginas mediante la anulación de un aprendizaje igualitario, fortaleciendo el aprendizaje diferencial de cada sexo ${ }^{[5]}$.

En resumen, el amor romántico es un constructo cultural que ha tenido sus inicios desde las antiguas civilizaciones, a travesando diferentes épocas culturales que han permitido modificar y perpetuar sus características hasta la época actual. Algunos autores definen el amor romántico como "indefinible" ya que abarca diversas características que, si se alejan de las teorías biológicas, sociológicas, filosóficas, entre otras, hay un hueco de conocimiento en el concepto actual que no es susceptible a medir. No obstante, en la población mexicana se sigue trasmitiendo a través de filmes extranjeros un ideal del amor romántico, siendo éste como algo omnipresente que es además una meta a alcanzar para poder lograr la felicidad, generando guías y pautas de comportamiento para hombres y mujeres correspondiente a lo aceptable como femenino y masculino. Después de todo éstas guías son percibidas como apropiadas por la población en general, en relación a los modelos reproducidos en la gran pantalla, y que generalmente son incuestionables a los pobladores, incluso para muchos de ellos aún son invisibles, por lo que a través de ellas se sigue reproduciendo el aprendizaje diferencial entre sexos, la violencia, la represión de las emociones, la esencia de cada persona en sí. Es evidente que socialmente la población es atravesada por un sistema político y económico capitalista que no deja posibilidad a seguir este ideal del amor romántico enseñado en pantalla, lo que genera frustración en la población, y más repercusiones sociales en el sistema.

Para concluir es fundamental cuestionarse acerca los filmes que se siguen viendo y reproduciendo, preguntar además que es lo que la sociedad está aprendiendo, así como promoviendo con sus iguales, asimismo visualizar las alternativas que se podrían elaborar para una mejor integración social sin divisiones de aprendizaje sexistas, así como factores que disminuyan la violencia, y la presión en los estereotipos de género. Yehuda Berg dijo alguna vez, la gran jugada del "diablo" fue hacerle creer a la humanidad que no existía, da a entender que el peor enemigo es aquel que es invisible a los ojos de las personas, no se puede combatir con algo que no se puede reconocer.

\section{Referencias}

[1] Serna J. De amory otras muertes horribles. San Luis potosí: Impresiones México; 2015, 17.

[2] Historia del amor a través de los tiempos [Internet]. El mundo al Instante. 2016 [Citado 26 de marzo de 2020] Disponible en: https://elmundoalinstante.com/historia-del-amor-tra ves-los-tiempos/ 
[3] Sangrador JL. Consideraciones psicosociales sobre el amor romántico, Psicothema. 1993; 5: 181-196.

[4] Bachoir O. El amor. En: Ponencia presentada en Alianza Francesa de Arequipa. Perú; 1993.

[5] Alonso MB, Manso JMM, Baamonde ME. Mito del a mor romántico en la tradición hispánica literaria y la violencia psicológica en la pareja, Puertas a la lectura, 2010; 22: 87-97

[6] NOWNESS. Romantic advice from French philosopher Alain Badiou. [Video] Estados Unidos; 2020.

[7] Martín I, Vega S, Rebollo S. El amor romántico en los productos audiovisuales de ficción, Admira: Revista de Análisis de Medios, Imágenes y Rela tos Audiovisuales, 2018; 6: 52-81.

[8] Gutiérrez V. Industria del cine crece más que la economía del país [internet]. El economista. 2019 [citado el 26 de marzo de 2020]. Disponible en https://bit.ly/2UpN7me

[9] Zaldivar M. La seducción de la Imagen, el impacto del cine extranjero (numero 29). Razón y Palabra. S.F. [citado el 26 de marzo de 2020] Disponible en https://bit.ly/34Gl1 Xm

[10] López A. La cultura a siática en el entretenimiento a través del comic el cine y el anime. El sol de México. 2018. [citado el 26 de marzo de 2020]. Disponible en https://bit.ly/3afm3uL

[11] García P. Los japoneses y el amor: claves del romance nipón. Cultura 2019 [Citado el 16 de abril de 2020]. Disponible en https://bit.ly/3bfcMnD

[12] Sierra C. Teoría Social del Aprendizaje de Albert Bandura. [Diapositiva]. Guadalajara: Universidad Antropológica de Guadalajara; 2016.15 diapositivas.

[13] Herrera C. Sin tiempo para el a mor: elcapita lismo romántico [internet]. Pikaza online Magazine. 2014 [citado 12 abril de 2020]. Disponible en: https://bit.ly/3ahw5vn

[14] Chayo JA. El mito, el ritual y la literatura. México: Universidad Autónoma de México; 2002.

[15] Herrera C. Los mitos del amor romántico en la cultura occidental. Madrid: El Rincón de 2007.

[16] Vox. Monogamy explained [Video]. Estados Unidos; 2018.

[17] Navarrete P. El mito del amor romántico y su pervivencia en la cultura de masas. Ubi Unt, 2013; 28: 100-109. 